感染具有抗病性, 是遗传性上已经纯化了的 抗 CMV 品系. 初步的田间实验证明，转基 因植株在自然条件下也表现出对 CMV 的抗 病性,春播的番茄, 9 月份当对照植株已全部 因病毒感染枯死时，而大部分转基因植株仍 继续生长结果. 表现了良好的生产潜力, 为 解决我国番茄等作物的病毒病开辟了新的途 径.

\section{*文 暗}

[1] Tien Po (田波), Chang, X. H. (张秢华), Seed
Science and Technology, 1983, 11: 969-972.

[2] Tien Po (田波) et al., Ann. Appl. Biol., 111 (1987), 143-152.

[3] 张春等,科学通报, 34 (1989), 7: 540 .

[4] 吴世宜等,中国科学, B 辂, 1989, 9: 945--956,

赵淑珍叶寅王昕王革矫 张秀华 张春是 徐雷新田波 (中国科学院微生物研究所, 北京 100080)

\title{
鲮鱼体细胞核的移植*
}

童第周等用衰胚细胞核作供体进行鱼类 细胞核移植. 在不同属的鲤 鱼 (Cyprinus carpio) 和銀鱼 (Carassius auratus) 之间, 在不同亚科的草鱼 (Ctenopharyngodon idellus) 和团头鲂 (Megalobrama amblycephala）之间，均曾获得核、质正反配合的杂种 鱼.

由于池养鲮鱼 (Cirrhinus molitorella) 的产卵期短而集中，难以找到产卵同步的其 他鱼作受体, 因此用鲮鱼竞肧细胞核与其他 鱼类的卵细胞质进行核、质杂交遇到了困难。 我们改用鿏鱼的体细胞核作供体，用鲤鱼的 去核卵作受体，进行核、质杂交试验。在 32 个移核卵中,有 21 个发育到共胚期, 占移核
卵总数的 $65.6 \%$, 其中有一个发育到心琎跳 动期, 存活 75h. 实验结果提示鲮鱼的体细胞 核在鲤鱼卵细胞质的活化下能促使移核后的 卵子正常分裂和发育, 并存在着发育成新个 体的可能性.

由于实验材料是取自鲮鱼身上的活 细 胞,直接移植到鲤鱼的去核卵内, 因此, 可以 克服供体鱼和受体鱼产卵不同步的困难, 这 将使鱼类核、质杂交的研究对象和组合大为 增加。

林礼堂 更任玲 朱新平 （中国水产科学研究院玶江水产研究所，广州 510380)

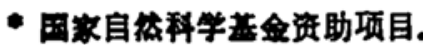

